\title{
Designing a model for measuring the impacts of successful outsourcing on organizations activities
}

\author{
Jamshid Salehi Sadagheienia $^{\mathrm{a}}$, Mehdi Kheirandish ${ }^{\mathrm{b}}$, Yasser Sobhani Fard ${ }^{\mathrm{c}^{*}}$, Maryam Akhavan \\ Kharazian $^{\mathrm{d}}$ and Mahdi Barkhordari Firouzabadi ${ }^{\mathrm{d}}$
}

${ }^{a}$ Department of Accounting \& Management of Allameh Tabatabai University, Tehran, Iran
${ }^{b}$ Department of Management, Shahid Sattari Air University, Tehran, Iran
${ }^{c}$ Imam Sadegh University, Tehran, Iran

${ }^{d}$ Isfahan University, Isfahan, Iran

A R T I C L E INF O ABSTRACT

Article history:

Received July 10, 2011

Received in Revised form

October, 3, 2011

Accepted 10 March 2012

Available online

9 March 2012

Keywords:

Violence against women

Esfahan

Family dispute

\begin{abstract}
A B S T R A C T
Outsourcing is known as using a supplier outside the organization in a way that this supplier provides the same service or goods provided normally inside the organization. Outsourcing likewise any other strategy has its own effects on the organization. This paper tries to evaluate the impact of a successful outsourcing on organization's activities in selected universities. In order to reach this purpose, after theoretical studies, first, obtained indexes by the expertise are evaluated and then by the confirmatory factor analysis with the help of Lisrel software, the claimed indexes are confirmed. The results of structural equation show that the questioned relevance is directly available and in some other words the implementation of a successful outsourcing will help improving organization's activities in the statistical.
\end{abstract}

\section{Introduction}

Outsourcing has become as one of the effective tools on reducing the unnecessary costs of production. There are literally different definitions for outsourcing. It can be defined as using a supplier outside the organization in a way that this supplier provides the service and goods, which were provided normally in the organization (Laabs, 2007). Gibson (1996) gives the other definition, which is transference of repetitive tasks to a supplier outside the organization. Another definition is to pay some money to other organization to accomplish some work. However, outsourcing is not precisely equal to an external contract, which emphasizes on allocating a work to a supplier individually or one by one. Outsourcing includes a long-term contract between suppliers and interested parties in an attempt to split the risk of production. According to Embleton and Write

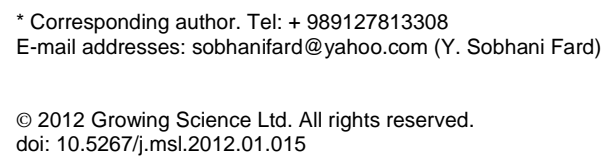


(1998) outsourcing is a concept where organizations look for specialties they can accomplish their business tasks as an external organization with its help.

Outsourcing does not only lead to physical affairs, because the businesses environmental conditions have turned into a way where outsourcing are virtually taken out in many aspects of business. One of the necessary questions in an organization is to find out the important factors influencing outsourcing and to determine the outcome of outsourcing. Johnson (1999) defined six steps for outsourcing, which are strategic analysis, determination of the best option, defining needs, selecting supplier, transferring operations and relationship management. Greavor (1999) explained five steps including primary planning, strategic considerations extraction, cost analysis, negotiation and requirements after the contract. Momme (2002) considered capability analysis, assessment and enterprise, contract negotiations, implement and transfer project, relationship management and closure management for a successful implementation of outsourcing. However, the main question is whether any of the mentioned hypothesis are performed, the implementation of outsourcing will lead to what kind of changes in the organization. One supposition proposed for this question is that implementing outsourcing will have positive impact on the organization's activities.

The first thing for reviewing the impact of outsourcing in an organization's activities is to highlight the activities, which are necessary for implementing a successful outsourcing. We also need to demonstrate the possible impacts of actions before representing a model explaining the relationship between the requirements of outsourcing and its effects.

\subsection{Effective factors in implementing a successful outsourcing}

In the implementation of a successful outsourcing, some activities must be taken place. For instance, before implementing outsourcing it is necessary to have some useful information about costs associated with the activities where outsourcing will occur. Some of the necessary items such as work, level of service, impact of organizational culture and actual cost of states such as insurance and tax costs must be considered very carefully. In addition, a full understanding of the current suppliers' level and type of service quality must be educated and then the level and type of the acceptable services must be acquired.

After we decided to implement outsourcing, the necessary decision is to select the outsourcing supplier. Inspecting the location and the situation of the supplier for at least once will help the organization make sure that the suppliers have appropriate capabilities. It is more efficient that in this inspection we concentrate on employees, organizational culture and cooperation process. It is better that a supplier is chosen which could adopt itself more efficiently than others do. In addition, both teams must agree on some options, which are easier and benefit both sides. Note that the final contract must not be set or no agreement should be signed suddenly or in rush. All the stages until the end of the task must be performed professionally as far as it is needed in the future (Foster, 1996). A method must be taken, which makes the management capable of supervising and analyzing the outsourcing contract.

Koh et al. (2004) presented a comprehensive study on successful implementation of outsourcings and observed that psychological contracts had completely different approaches compared with legal and traditional contracts. The meaning of being mutual in this study is that both sides have in common beliefs in being committed towards each other (Rousseau, 2001).

In order to gain success in implementation of outsourcing, the management should consider items such as mission statement, culture, trade union organization environment, future needs of work force, current skills of work force, competence and current and target organizational structure

In summary and according to mentioned studies, the following factors can be used for successful implementation 
A) Primary planning: It is important to determine the minimum quality service required for outsourcing.

B) Strategic analysis: It is necessary to look for strategic directions of the supplier, inspection from situation and location of the supplier, having competitive advantage from the supplier in the desired task

C) Cost analysis: One important component of outsourcing is to analyze different costs involved with outsourcing some activities.

D) Negotiations: All negotiations must be accomplished in a way that both sides feel to be the winner, creating a mutual trust between the university and the supplier

E) Requirements of the post contract: It is important to transfer the surplus employees to the supplier company, providing facilities for the supplier, continuous control function of the supplier.

\subsection{The impacts of outsourcing on the organizations activities}

Outsourcing has several impacts on the organizations activities and the intention is the opinion of some organizations, which started implementing outsourcing. Many researchers have tried to expand their researches about the advantages resulted from outsourcing within these positive effects, the input impacts on the organization's activities are extracted.

For example, Hassanain and Al-Saadi (2008) explained the following items as important factors for successful implementation of outsourcing such as improvement in service quality, reduction in costs in long-term service delivery, specialized education and professional skills, etc. Alpesh and Hemendra (2007) identified other important factors such as cost reduction, central competence, increase in organizational efficiency, accessing the best talents and technologies, improvement in service quality, transferring risks and hazards related to the organizations development to other, increase in the capability of recovery towards unpleasant accidents and continuity of the program in such cases, expedition in huge organizational distribute.

Lower costs (Young, 2005), accessing professions and experiences (Khalfan, 2004), increase in level of service and efficiency (Domeberger, 1998), more concentration on central activities (Graham \& Scarborough, 1997), increase in flexibility (O.Looney, 1998), reducing the problems caused by industrial relationships, risk sharing (Gabig,1996; Graham \& Scarborough, 1997)

Researches accomplished by cost finding studies show that costs associated with employees is the second cost making variable in the organization. This part of share becomes more and more important in industries associated with service in a way that this cost is assigned as the first rank in the organizations total costs.

The main advantage of outsourcing is that it causes the organization to only engage in its central competence (Petrie, 2000). One of these effects is the impact that outsourcing has on the spirit of the organization (Petrie, 2000). In case of outsourcing, if dispatching the employees to the outsourcer causes decrease in the costs of the organization, then this process is necessary. In a summary, the effects of implementing outsourcing on the organizational activities can be classified into four categories of organizational activity mentioned below:

A) Human resources activity: Reducing the need for experts in organization, reducing the need for headquarters, reducing in mental damages to employees, improving the social view from the 
organization, learning new professions, more responsible staff, reduce in staff's capability and experience,

B) Marketing activity: Reducing costs of competition, increasing customer integration, and reducing the lag of competitors, increasing the volume of orders, expedition in service delivery, reducing the costs of long-term service delivery,

C) Financial activity: Reducing costs, better control of resources, better forecasting of costs, converting fixed costs to variable ones, reducing contract costs, reducing liquidity costs,

D) Internal activity: Increasing control on affairs, reducing security threats in the confidential information field, increasing attention to long-term prospect of organization, creating innovation and creativity in order improve processes, focus of the organization on its central competence, creating formal and forums standards of work, easy planning, reducing bureaucracy and administrative red tapes, better utilization of capacity.

The rest of this paper is organized as follows. We first present details of the proposed study in section 2 and details of our finding are given in section 3. Finally, concluding remarks are presented in the last section to summarize the contribution of the paper.

\section{Statistical methodology and community}

The survey designed a questionnaire and distributed among some experts in two regions of Qazvin and Isfahan. In this research, all questions are designed on Likert scale. The sample size is calculated using the following,

$$
n=\frac{N \times z_{\alpha / 2}^{2} \times p \times q}{\varepsilon^{2} \times(N-1)+z_{\alpha / 2}^{2} \times p \times q},
$$

where $N$ is the population size, $p=1-q$ represents the yes/no categories, $z_{\alpha / 2}$ is CDF of normal distribution and finally $\varepsilon$ is the error term. Since we have $p=0.5, z_{\alpha / 2}=1.96$ and $N=250$, the number of sample size is calculated as $n=175$. In our method, we first review the items and prioritize them based on their relative importance. Next, we use Lisrel software to perform confirmatory factor analysis and we also use Cronbach Alpha (Cronbach, 1951) to validate the results.

\section{Data analysis}

In this paper, we have used Likert based scale and any number greater equal to three is considered to be significant. As we explained earlier, the feedbacks are gathered from the university professional perspectives. There are 19 items considered as important factors, which are summarized in Table 1. Note that the null hypothesis for all 19 items is that the average score is equal to three and alternative hypothesis is associated with the numbers, which are either lower or greater than 3 .

1- As a result of the sig number being smaller than five percent in indexes number 10,11 and 18,the average is not equal to 3 , and because the numbers of high and low are both negative so the community average is inferred to be lower than 3 . Therefore, these indexes do not influence outsourcing, significantly.

2- As a result of the sig number being bigger than five percent in indexes number 4,7,12 and 17, the average is equal to 3 and these indexes are assumed to have a medium rate of importance and will affect on further calculations. 
3- As a result of the sig number being smaller than five percent in indexes number $1,2,3,5,6,8,9,13,14,15,16,19$, with the numbers of high and low being positive, the community average for these indexes is inferred larger than 3 . Therefore, these indexes have high rates of importance and will affect on further calculations. In other words, their assumption is acceptable.

\section{Table 1}

The results of different hypothesis

\begin{tabular}{|c|c|c|c|c|c|c|c|}
\hline $\begin{array}{l}\text { Indexes } \\
\text { number }\end{array}$ & indexes & statistic & $\begin{array}{l}\begin{array}{l}\text { Freedom } \\
\text { degree }\end{array} \\
\end{array}$ & significant & 95\% certainty & & \\
\hline & & & & & Low Limit & $\begin{array}{l}\text { High } \\
\text { Limit }\end{array}$ & result \\
\hline 1 & $\begin{array}{l}\text { The required level of quality service } \\
\text { assessment }\end{array}$ & 24.340 & 161 & .000 & 1.4917 & 1.7552 & accept \\
\hline 2 & Expectations of the client from services & 14.574 & 161 & .000 & 1.1046 & 1.4509 & accept \\
\hline 3 & Standardization of the process & 12.420 & 161 & .000 & .8358 & 1.1518 & accept \\
\hline 4 & $\begin{array}{l}\text { Coordination of infrastructures in the } \\
\text { university }\end{array}$ & -.870 & 161 & .385 & -.3431 & .1332 & accept \\
\hline 5 & Support from top management & 5.365 & 161 & .000 & .3550 & .7685 & accept \\
\hline 6 & Current situation assessment & 26.651 & 161 & .000 & 1.5432 & 1.7902 & accept \\
\hline 7 & Cultural issues from the contract & -1.219 & 161 & .225 & -.3720 & .0880 & accept \\
\hline 8 & Targets limitations & 10.098 & 161 & .000 & .6952 & 1.0332 & accept \\
\hline 9 & Cost/benefit analysis & 11.760 & 161 & .000 & .8218 & 1.1535 & accept \\
\hline 10 & $\begin{array}{l}\text { Identifying the strategic directions of the } \\
\text { supplier }\end{array}$ & -9.588 & 161 & .000 & -1.2357 & -.8136 & reject \\
\hline 11 & Supplier inspection & -12.83 & 161 & .000 & -1.4530 & -1.065 & reject \\
\hline 12 & Supplier financial evaluation & 1.593 & 161 & .113 & -.0415 & .3871 & accept \\
\hline 13 & Supplier's competitive advantage & 13.333 & 161 & .000 & 1.1727 & 1.5804 & accept \\
\hline 14 & Service cost determination & 10.281 & 161 & .000 & .7281 & 1.0743 & accept \\
\hline 15 & Feeling win-win for both sides & 14.063 & 161 & .000 & .9710 & 1.2883 & accept \\
\hline 16 & Mutual trust between customer and supplier & 41.127 & 161 & .000 & 1.5161 & 1.6691 & accept \\
\hline 17 & $\begin{array}{l}\text { Transferring the surplus employees to } \\
\text { supplier company }\end{array}$ & -1.961 & 161 & .052 & -.4213 & .0015 & accept \\
\hline 18 & providing facilities for the supplier & -8.766 & 161 & .000 & -1.1723 & -.7413 & reject \\
\hline 19 & Continuous control function of the supplier & 26.025 & 161 & .000 & 1.5744 & 1.8330 & accept \\
\hline
\end{tabular}

According to the mentioned results only the indexes 10, 11 and 18 are omitted from further calculations. In other words, their assumptions associated with being important in evaluating the effectiveness of outsourcing will not be confirmed, which yields the following conclusion,

A) Identifying the strategic directions of the supplier does not have required importance in evaluating outsourcing.

B) Inspecting the situation and location of the supplier do not affect in evaluating outsourcing.

C) Providing facilities for the supplier does not have the required importance in evaluating outsourcing.

In other words, although these three results are confirmed in books and articles as indexes used for evaluating outsourcing, in statistical community these indexes are not appropriate due to special terms and conditions and the type of special outsourcing contracts. Thus, three above indexes are omitted from further calculations. There are other secondary issues influencing outsourcing and we 
have also performed our survey to examine the effects of them. Table 2 shows details of our survey for these issue.

Table 2

Details of survey results

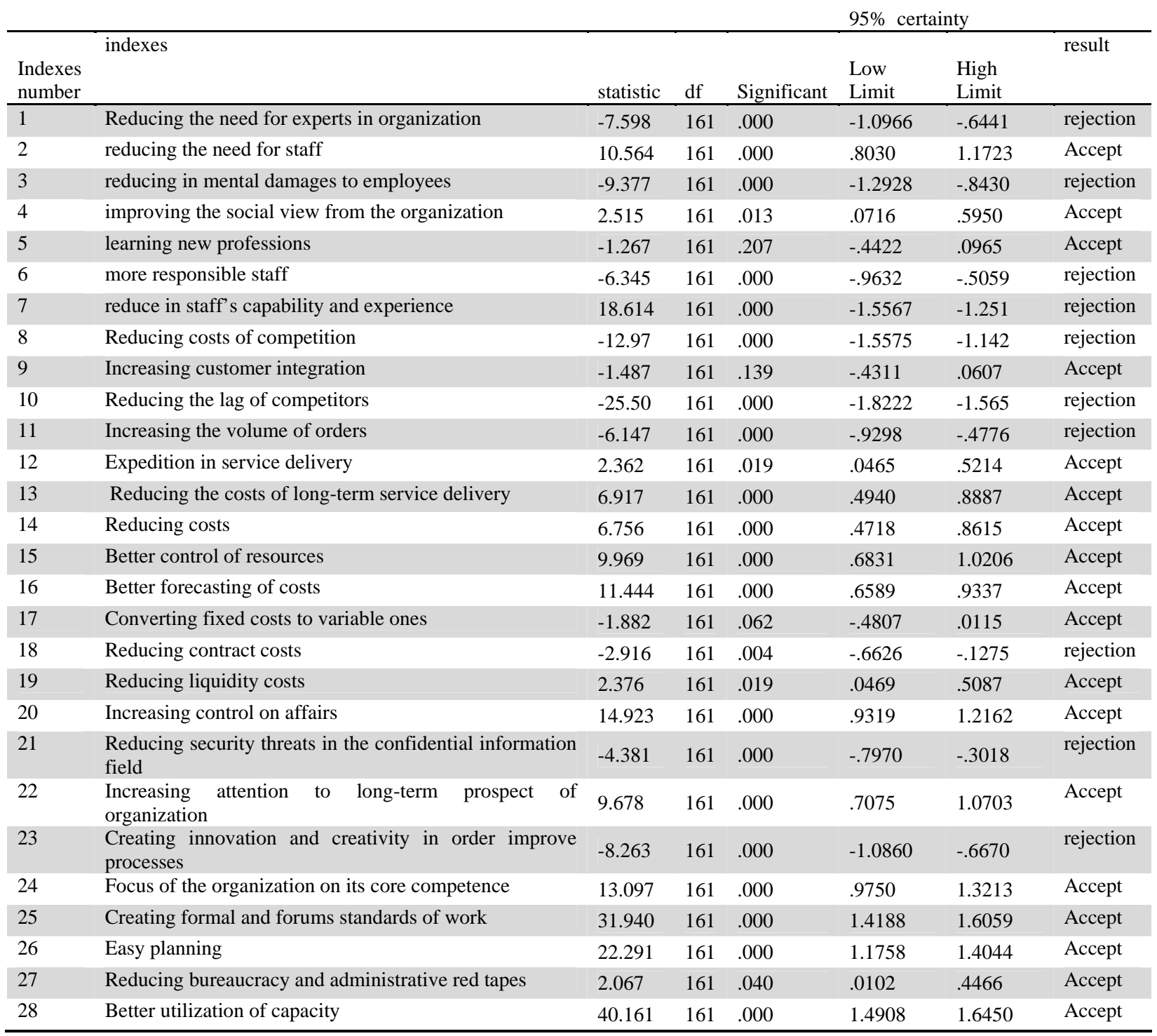

The null hypothesis for 28 hypotheses are similar to what we used for the main questions specified in Table 1 . The following summarizes the results of our hypotheses.

1-As a result of the sig number being smaller than five percent in indexes number 1,3,6,7,8,10,11 $, 18,21,23$ the average is not equal to 3 , and because the numbers of high and low are both negative so the community average is inferred to be lower than 3 . So these indexes do not have the importance for implementing effective outsourcing.

2- As a result of the sig number being bigger than five percent in indexes number 5 and 9, the average is inferred to be 3 and these indexes are assumed to have a medium rate of importance and will have influence on further calculations. In other words their assumption which matches the default zero is acceptable. 
3- As a result of the sig number being smaller than five percent in indexes number $2,4,12,13,14,15,16,17,19,20,24,25,26,27,28$ with the numbers of high and low being positive, the community average for these indexes is inferred larger than 3. Therefore, these indexes have a high rate of importance and will affect on further calculations. In other words, their assumption is acceptable. According to the mentioned results only the indexes 1, 3, 6,7,8,10,11,18,21,23 are omitted from further calculations. In other words, their assumption related to being important in evaluating the effectiveness of outsourcing will not be confirmed.

\subsection{Confirmatory factor analysis for outsourcing and organizational activities variables}

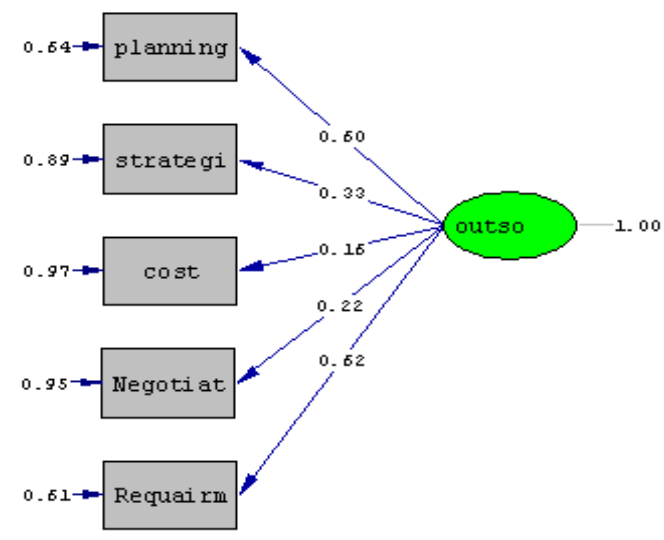

Fig. 1. Confirmatory factor analysis for outsourcing variables and activities, Chi-square $=19.37, \mathrm{df}=5, \mathrm{P}-$ value $=0.00164$, $\mathrm{RMSEA}=0.034$

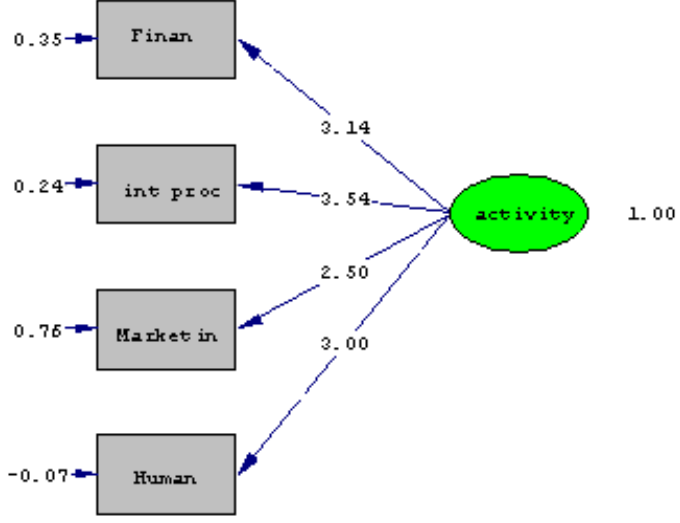

Fig. 2. confirmatory factor analysis for organizational activities variables, Chi-square $=17.45, \quad \mathrm{df}=6, \quad \mathrm{P}$ value $=0.0000$, $\mathrm{RMSEA}=0.041$

As we can observe from the results of Fig. 1 and Fig. 2, four variables of human resources, marketing, financial and internal processes and five variable of primary planning, strategic analysis, cost analysis, negotiations and requirements of the post contract are the ones that can measure the changes made in internal processes because their credit has been confirmed by the factor analysis. RMESA and P-VALUE values, chi-square than degrees of freedom and statistic value of $t$, all approve the confirmatory factor analysis.

\section{C) Reviewing the effect of outsourcing on organizational activities}

After specifying important indexes in measuring outsourcing and the impacts outsourcing has on organizational activities and after confirmatory factor analysis it is now turn for the last part of the research which within our structural equations are reviewed between the hidden variables of the model, outsourcing and organizational activities. Chart.3 shows us this structural equation. 


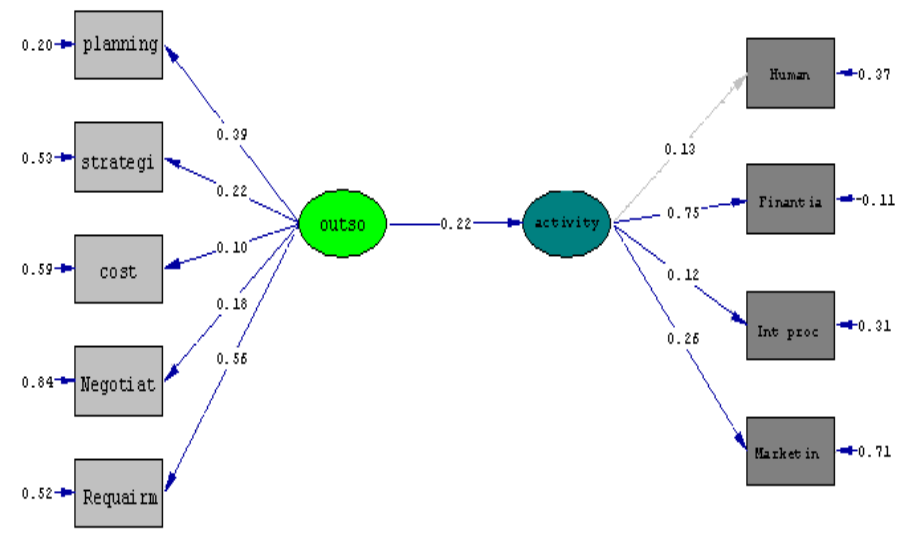

Fig. 3. Structural equations between outsourcing and organizational activities variables

Fig. 3 shows details of our structural equations between outsourcing and the variables of organizational activities. The minimum fit function chi-square is 74.90 with $p=0.00$, normal theory weighted least square Chi-square is 76.70 with $p=0.00$, estimated non-centrality parameter (NCP) is 50.70, minimum fit function value is 0.47 , population discrepancy function value is 0.31 and adjusted fitness function index (AGFI) is 0.83. Based on these results, we can conclude that there is a relationship among the hidden variables of this research, outsourcing and service quality. Standard coefficients of all the paths are shown in Fig. 3.

\section{Conclusion}

The results from analyzing the research data's show these results:

Indexes which with the help of them we can evaluate successful outsourcings in a statistical community of research are mentioned below:

\section{A) Primary planning}

Determining the required level of quality service from the university's site of view, determining the expectations of the client from services, standardization of the process, coordination of infrastructures in the university, attract support from top managers of the contract.

B) Strategic analysis

Analyzing the current situation about service, paying attention to cultural issues from the contract, bringing few targets in the contract, identifying the strategic directions of the supplier, inspection from situation and location of the supplier, having competitive advantage from the supplier in the desired task

\section{C) Cost analysis}

Financial analysis of the supplier, determining the costs of service, checking financial justification of the contract

D) Negotiations

Performing the contract negotiations in way which both sides feel to be the winner, creating a mutual trust between the university and the supplier 
E) Requirements of the contract

Transferring the surplus employees to the supplier company, providing facilities for the supplier, continuous control function of the supplier.

2-indexes which could be mentioned as important impact of outsourcing on organizational activities in a statistical community of this research are:

\section{A) Human resources activity}

Reducing the need for experts in organization, reducing the need for headquarters, reducing in mental damages to employees, improving the social view from the organization, learning new professions, more responsible staff, reduce in staff's capability and experience

B) Marketing activity

Reducing costs of competition, increasing customer integration, and reducing the lag of competitors, increasing the volume of orders, expedition in service delivery, reducing the costs of long-term service delivery

C) Financial activity

Reducing costs, better control of resources, better forecasting of costs, converting fixed costs to variable ones, reducing contract costs, reducing liquidity costs

D) Internal activity

Increasing control on affairs, reducing security threats in the confidential information field, increasing attention to long-term prospect of organization, creating innovation and creativity in order improve processes, focus of the organization on its central competence, creating formal and forums standards of work, easy planning, reducing bureaucracy and administrative red tapes, better utilization of capacity

3-The main assumption of the research has been confirmed so it can be said that implementing a more and more successful outsourcing will cause an improvement in organizational activities. According to this we can have conclusion that if in an organization five indexes of planning, strategic analysis, cost analysis, negotiations and requirements after the contract are provided and these indexes are performed in an appropriate way then we will have an improvement in human resources, marketing, financial and internal activities in result.

\section{References}

Alpesh B. P., \& Hemendra A. (2007). Outsourcing success: The Management Imperative. Great Britain, Palgrave Macmillan.

Cronbach, L. J. (1951). Coefficient alpha and the internal structure of tests. Psychometrika, 16(3), 297-334.

Embleton, P.R., \& Wright, P. C. (1998). A practical guide to successful outsourcing. Empowerment in Organizations, 6(3), $94-106$. 
Domberger, S. (1998). The Contracting Organization - A Strategic Guide to Outsourcing. Oxford University Press, Oxford.

Gabig, J.S. Jr (1996). Privatization: a coming wave for federal information technology requirements. National Contract Management Journal, 27(1), 9-23.

Gibson, V.M. (1996). Outsourcing can save money and increase efficiency”, Benefits Administration, March, p. 19.

Graham, M., \& Scarborough, H. (1997). Information technology outsourcing by state governments in Australia. Australian Journal of Public Administration, 56(3), 30-9.

Greaver Maurice (1999). Strategic Outsourcing: A Structured Approach to Outsourcing Decisions and Initiatives. American management association international ,brodway New York

Johnson, G \& Scholes, K. (1999). Exploring Corporate Strategy. Tex and case, $5^{\text {th }}$,Prentice-Hall

Khalfan, A.M. (2004). Information security considerations in IS/IT outsourcing projects: a descriptive case study of two sectors. International Journal of Information Systems, 24, 29-42.

Koh, K., Ang, S., \& Straub, D. (2004). IT outsourcing success: A psychological contract perspective. Information Systems Research, 15(4), 356-373.

Laabs, J.J. (1996). Successful outsourcing depends on critical factors. Workforce Online Research Centre,

Hassanain, M.A., \& Al-Saadi, S. (2008). A framework model for outsourcing asset management services. Facilities, 23(1/2), 73-81.

Jesper, M., \& Henrik, H. (2002). An Outsourcing Framework: Action Research in the Heavy industry Sector. European Journal of Purchasing and Supply Management, 9.

O’Looney, J. (1998). Outsourcing the City: State and Local Government Outsourcing. Quorum Books, New York, NY.

Embleton, P.R., \& Wright, P.C. (2008 ). A practical guide to successful outsourcing, Empowerment in Organizations, 6(3), 94-106

Petrie, D. (2000). Outsourcing: risky business?. Accounting and Auditing Solutions.

Rousseau, D. M. (2001). Schema, promise, and mutuality: The building blocks of the psychological contract. Journal of Occupational and Organizational Psychology, 74(4), 511-541.

Young, S. (2005). Outsourcing in the Australian health sector: the interplay of economics and politics. International Journal of Public Sector Management, 18(1), 25-36. 